\title{
ROLE OF FOOD TRADITION IN CONSERVING CROP LANDRACES ON-FARM
}

\author{
Deepak Kumar Rijal, PhD ${ }^{1}$
}

\begin{abstract}
Local knowledge of crop diversity linked to food traditions, local practices and social norms is documented acquired through interaction with farmers and focus group discussion. Cooking quality of different rice varieties was assessed to see the effects of the environment factors. Different food dishes were assessed by trained cook, urban and rural consumers to identify dishes for market promotion. Diversified food traditions show close links to richness of crop landrace diversity. Crop landraces have substance, symbolic and sign values. Certain food dishes are used as symbolic offerings to different Gods such as lineage God, goddess and spirits of the past ancestors. Of the elaborated dishes tried, taro when prepared with legumes, mutton and fish, was preferred. Such preference was also landrace specific. 'Hattipow' for fried mutton, 'Panchamukhe' with fish and 'Ujarka' for Samosa are preferred. Culinary characters on rice landraces were unaffected by environment factors. The quality of improved variety, however decreased when grown in alien environments. The likelihood of crop landraces to be conserved increases if: a) they are competitive to other options farmers-custodian have b) farmer-custodian and consumers follow socio-cultural norms, and c) traditional dishes still remain popular. Increased demand for landraces and the promotion of landraces derived products help generate income and green jobs which are the same time offers of community incentives to conserve crop landraces on-farm.
\end{abstract}

Key words: Dishes, landraces, livelihoods, traditions, values

Considering food as a "driving force" for conserving biodiversity, Carlo Petrini (2000) stated that we cannot just be food lovers ... we must be there where it is most at risk as in the developing world (Slow Food, October 2000, BBC Online).

\section{INTRODUCTION}

Food traditions carry a variety of meanings and are potent expression of those locally adopted social norms. In a society, food is a substance that can be both a symbol and a $s i g n^{2}$. The symbolic meanings of various foods are derived primarily from the roles they play in economic life. Food often symbolises visible indices of wealth, ethnicity and social well being of the people. In other word, meal structures are the reflection of the immaterial life. Food signifies social norms and values as expressed in metaphoric languages. Hence, food can also be seen as a social indicator. Douglas (1997) stated that if food is treated as a code it encodes the pattern of social relations expressed in varying degrees of hierarchy, inclusion or exclusion and transactions across social boundaries. Marcel Mauss (1967) describes food as a 'total social fact'. The ways food dishes are chosen and the special dishes used as symbolic offerings vary by ecological, social and economical variables. In totality, food traditions decode social systems. Along with economic benefits, the maintenance of crop landraces is also linked to peoples' cultural, social and ritual values. To be specific, food traditions are often connected to the cultivation of crop landraces since they co-evolved, shaping each other. It was observed that foods and food traditions have changed in response to changes in social norms and interests. The degree of change, however, depended largely on consumers' access to information that corresponds to diet in terms of preference and perceived benefits.

\footnotetext{
1 rijal.deepak@gmail.com, +977 15522 354, CADP-Nepal, Sanepa 2 Lalitpur, Nepal

${ }^{2}$ Symbol and sign refer here to food in their roles as elements in the cuisine (Weismantel, 1988).
} 
Preliminary research results indicate that the likelihood of crop landraces being conserved increases when the market for their derived products are expanded through improved consumer access to information on recipes, nutritive and cultural values (Rijal, et al., 1999). In the first section of this article, are discussed links between food tradition and the conservation of crop landraces on-farm. The possible impacts of improved or elaborated dishes with regard to on-farm conservation of landraces of rice and taro in Nepal are also discussed.

\section{DEMAND AND SUPPLY OF CROP LANDRACES}

Farmers cultivate landraces that have both symbolic and social values together with economic benefits. The total costs and benefits of landraces to cultivating households are central to their conservation on-farm (Brush and Meng, 1998). Farmers maintain crop landraces if these are valued either for economic, cultural, social, or ecological reasons (e.g. Zimmer and Douches, 1991; Bellon and Taylor, 1993). In fact, reliable supply and producer-consumer linkages are realized constraints relating to the promotion of local crop based dishes. Unlike farmers, urban consumers are poorly informed on nutritive and cultural values of traditional dishes. In total, locally prepared products poorly qualify to attract new consumers especially in urban areas where they are exposed to a variety of choices for food dishes. However, it has been suggested that the demand for crop landraces and their derived products may be expanded through improved markets that promote consumers' awareness and policy support (Jarvis and Hodgkin, 1997).

Till date, 'productivity' has been the basis for selecting varieties in agricultural research. Since the promotion of modern varieties, most crop landraces have either been displaced from their natural habitats and / or grown in reduced areas. Smale (2000) reviewed rice landraces reserved in relatively small sizes, in patches or islands of farming systems (Brush, 1995:246), micro-centre of diversity (Harlan, 1992:147) and in decreased areas (Rijal, et al., 1999) particularly when modern varieties were widely adopted. Richness of diversity is maintained together with ecosystem, ethnicity and consumers' preferences. The key issue is that whether landraces thus displaced from their original habitats can be successfully grown under alien environments where farmers' options are limited. Their on-farm conservation is therefore dependent on how landraces are competitive in providing benefits, regardless of habitat types. It may be hypothesized that the elaboration of traditional dishes combined with improved access of consumers to associated information provides farmers incentives for on-farm conservation of landraces. The specific questions asked in this article include: a) How are food traditions linked to conservation of crop landraces? b) How does increased knowledge on food traditions / improved dishes help create / expand market demand? and c) Do environmental factors have any impact on eating quality of rice?, and d) how does this accrued knowledge imply to livelihoods together with on-farm conservation? To address some of these questions, a study of food traditions and research was initiated with reference to food dishes of rice and taro in Nepal.

\section{STUDY SITES}

Since food traditions vary between locations and societies, distinct natural and social aspects of the study villages are described. Food traditions discussed in this article have been collected from three contrasting villages located in High Hill, Mid Hill and Terai in Nepal.Talium village in Jumla district is located above 2240 meters. The climate is subalpine to temperate. The mean temperature is recorded at $12^{\circ} \mathrm{C}$, and snow in winter is common. Rainfall is recorded around $850 \mathrm{~mm}$ per year. The snow is considered as an important source of water for winter crops as well as crops to be planted during spring season. Begnas village is located $15 \mathrm{~km}$ northeast from Pokhara in western region. It has warm temperate to sub-tropical climate. The village extends between $669 \mathrm{~m}$ and 1430 meters in altitude. A mean temperature of $20^{\circ} \mathrm{C}$ and a total rainfall of $3999 \mathrm{~mm}$ per year is 
recorded. Indo-Aryans ${ }^{1}$ form a major fraction of the society although a minority of TibetoBurmans $^{2}$ inhabited there. Kachorwa village is located in Bara district. The climate is subtropical and the mean temperature is $25^{\circ} \mathrm{C}$. The altitude is 80 meters. Rainfall is around $1500 \mathrm{~mm}$ a year. Throughout all of the villages, above 70 per cent rainfall is received during June - September (Poudel, et al., 1999).

Like Begnas, almost all inhabitants in the rest of the villages are Indo-Aryans whose livelihoods are primarily dependent on crop production. In these study areas farmers have been cultivating different named rice and taro varieties. Among these villages, there is greater variation of rice and taro diversity in Begnas followed by Kachorwa and Talium. This diversity generally corresponds to dietary richness including local dishes. The above description shows that variation exists between villages both for natural and social factors. Variation in access to market and roads across villages has further influenced the status of crop landraces linked to food traditions.

\section{RESEARCH METHOD}

This research is divided into three parts. The first part describes landraces linked to food tradition. This knowledge had been acquired using participatory approaches including focus group discussion, direct observation and interaction with local informants. The second part describes the formulation of new recipe development and organo-leptic tests using panel members. The third part of the research briefly elaborates reciprocal testing of landraces to see environmental effects on the cooking quality of rice varieties.

\section{ACQUISITION OF TRADITIONAL KNOWLEDGE}

In the first place, materials related to Nepalese food traditions, their meanings and traditional dishes are described, and research data on traditional dishes thereafter. Materials were gathered through researchers' field experience, observation and focus group discussion (FGD) with farmers. In each FGD, 8-10 "nodal farmers" ${ }^{3}$ " (Subedi et al., 2001) were involved. The majority of farmers who participated in the discussion were female farmers who had most knowledge about food traditions. However, those known male cooks identified locally were also invited. Through observation and FGD, farmers' ways of describing meals and the elements were gathered. Information on the patterns foods are served, the ways local dishes are prepared and the seasons they are consumed was also inventoried. The case studies are basically food traditions related to rice and taro.

\section{SENSORY EVALUATION OF TARO DISHES}

Topical focus group discussions were held with experts such as cooks, marketers and service providers. Since marketers are familiar with consumers' preferences, inclusion of their perspectives in the research process was assured. The scope and need for elaboration of local dishes were explored. The group identified few potential dishes for elaboration. Locally known taro landraces from Begnas and Kachorwa were used in popular urban dishes, namely curry, dip fry and Samosa ${ }^{4}$. Three popular landraces, 'Panchamukhe' and 'Hatipow' from Begnas and 'Ujarka' from Kachorwa were chosen. They were tried with a variety of ingredients mainly fish, mutton and legumes. The snack dish 'Samosa' was tried with 'Ujarka', a known landrace in place of potatoes. Different combinations of tested dishes are presented in Annex 1. These dishes underwent organo-leptic evaluation.

\footnotetext{
${ }^{1}$ Genetically identifiable race with long nose and deep eyes of Indo-Aryan origin and follow Hinduism

${ }^{2}$ Genetically identifiable race with flat nose, Tibeto-Burman origin primarily follow Buddhism

${ }^{3}$ Nodal farmers are innovative, knowledgeable and those maintaining high number of crop landraces and also provide services

${ }^{4}$ Popular snack in plain Tarai, a triangular shaped dish prepared by mixing mashed potatoes, spices, chopped onion, which is wrapped by thin layer of wheat flour and dip fried in oil.
} 
To assure consumers' representation, three panel groups representing farmers-custodian, urban housewives, and expert cooks were assembled. In urban and rural societies, women, as most known cooks are still women, were invited for the evaluation. Other members already familiar with traditional dishes were also invited. Since hotel cooks are familiar with the wide range of consumers' taste, from local elites through to outsiders, they were invited for evaluation.

Through the discussions, five parameters namely taste, colour, appearance, texture and aroma were considered. Prior to being served dishes, panel members were briefed on the evaluation system. The panellist ranked dishes as good (5), medium (3) or poor (1) according to the parameters. The panellists rated items using appearance, texture, softness, taste and cooking quality. The weight was estimated using a formula: rank assessed by individual panel response $x$ individual score for each good (5), medium (3) and poor (1) category (Devinder Singh, e-mail comm, 2002). The experiment was conducted in Pokhara Tourism Training Centre and involved local farmers and panellists from around Pokhara.

\section{ASSESSING EFFECTS OF ENVIRONMENT FACTORS ON RICE COOKING QUALITIES}

In this section we explore how farmers adapt landraces to suit food traditions under variable environments. To understand preference variation, examples with rice landraces linked to food traditions are discussed. 'Jumli marsi' a landrace native to Jumla is well known for cooked rice. It is said that a visit to Jumla becomes memorable if one tries rice from 'Jumli marsi' served with mutton and bean soup. Despite a brown grain colour, low grain yield, and coarse grain (Rijal, et al., 2003), 'Jumli marsi' remains a popular landrace. For this reason 'Jumli marsi' fetches premium price. 'Anadi rice' landrace, native to Begnas with sticky, coarse and chalky grains, makes a special dish locally known as 'Latte'. This dish is served on specific occasions. Despite low yield, Begnas farmers still grow another aromatic, fine grain rice landrace 'Jhinuwa' is another landrace known for its quality. The above landraces are grown under fertile lands with irrigation. Despite contrasting characters, these landraces fetch premium prices in local markets. That means that the grain price does not necessarily indicate grain quality, but the specific use value determines market price. It was learned that 'Anadi' along with other landraces grown in the uplands such as 'Rato ghaiya', are considered impure and, therefore not accepted in social or religious functions. By contrast, fine and aromatic landraces grown with irrigation are acceptable for such social functions. It would seem that upland rice landraces are primarily maintained on economic grounds rather than cultural and further that rice landraces with cultural values are cultivated under irrigated ecosystems. This is important to know as landraces are being displaced by so called high yielding modern varieties. It is unknown whether or not culturally valued landraces can be grown in marginal or upland areas where options are limited.

To see the effects of moisture regimes on culinary characters, three distinct rice varieties were studied. Locally defined moisture regimes include Sinchit (irrigated), Tari (rain fed) and Ghaiya (upland). Culinary characters of 'Anadi' and 'Jhinuwa' were compared with an improved variety Khumal 4, grown across all ecosystems. The above cultivars are native to irrigated low land. Ten panellist farmers invited from Begnas evaluated landraces for cooked rice.

\section{STUDY FINDINGS}

The research results are presented in three sub-sections. In the first section the knowledge acquired on local diversity of landraces and food traditions including food habits are

\footnotetext{
${ }^{1}$ generally fried with ghee to which substances like sugar, spices, and medinical herbs are added
} 
described. In the second section results from of panel assessment of taro dishes are elaborated. Cooking qualities of rice landraces assessed over environment factors are presented in section three.

\section{NEPALESE FOOD TRADITIONS}

Nepalese foods can be grouped into 'primary' and 'secondary' meals, as suggested by Douglas (1997). Of these, two main meals are here termed 'primary meals'. A complete meal consists of dishes from cereals, legume, vegetable, milk or ghee and pickle. The most common meal consists of 'Daal' (Legume soup), 'Bhat' (Boiled rice or maize grits or gruel) and 'Tarkari' (vegetable fry or curry), both in urban and rural settings. Pickles with hot and sour tastes are other desirable elements. Nepalese food traditions are complex and they vary by location, ethnic group and consumers' preferences.

It was known that the dishes forming a meal differ from one village to another. The common dishes for primary meals are derived from wheat or maize and legumes. The meat items are, however, served occasionally on non-ritual festive and ceremonies. Such dishes are considered energy giving. To allow proper digestion, one needs rest and, therefore, heavier meals are eaten in the evening. The dishes served at different times vary from one location to another depending upon the crop varieties grown. A glimpse of local dishes served at different times of the day is presented in Annex 2.

The dishes served each time differ from one another. In all villages, tea is served with milk and sugar particularly to guests and thirsty family members. Tea as a common drink is served in any gathering or function. Farmers experience that milk tea with strong sugar gives instant energy. Tea for this reason is sometimes served instead of a snack, particularly when a meal will be served late.

In villages, farmers adopt a variety of ways to fulfil dietary requirements. The selection of elements for the later meal depends on what was included in the previous meal. Unlike primary meals, secondary meals locally known as 'Khaja' are light and served twice a day, as breakfast or a midday snack. However, 'Khaja' among rural inhabitants is served only under specific conditions. It is served to members going out who expect to be late back to join in family meal or because the forthcoming meal will be served late. Midday snacks are heavier than those eaten as breakfast. Midday snacks are popular among farm workers as they are eaten to regain lost energy. The locations where specific items served as breakfast and midday snack are presented in Annex 2. Beaten rice, yoghurt and fried potatoes are such common and preferred snacks served at breakfast or midday, however, instead of beaten rice, boiled potatoes and bread prepared from millet, barley or wheat are common where rice production is very low. It was also learned that some rice landraces are preferred for beaten rice than others.

Milk is an inseparable element in Nepali dishes. Since farmers keep a few animals, milk may not be available all the time. When milk is in short supply, it is mainly served to physically weak members such as elderly people and young children. The present study on food culture shows a varying degree of associations between dietary richness and the amount of crop diversity at species and intra-species levels. The maintenance of local crop diversity also interacts with other components such as livestock. Increased production of milk and milk products can motivate consumers for using beaten rice, which in turn can provide farmers' incentives to grow suitable rice landraces. In other words, the maintenance of traditional dishes derived primarily from local crop diversity will maintain on-farm diversity.

\section{PATTERNS OF SERVING FOOD}

The meaning of eating differs with regard to the dishes that form a meal and to the ways a meal is served. The dietary diversity varies over locations, which across all villages has 
been both symbol and sign. Apart from wealth, caste and education, the elements that form a meal and the ways meals are served indicate household prestige. The dishes to be served vary directly by age group, nature of jobs they do, and by positions they hold in the society. The household cook ('Bramhin') who serves guests with a variety of dishes in a brash plate and with cups on clean mats, spread all on cow dung smeared floor, symbolises respect. Certain norms are followed in serving meals. Heads of the household and guests are served first but other key family members may join in provided there is enough space. The same cuisine is served to those members who enjoy meals together. Those are elite members receive priority for food that is more appealing, attractive and energy - giving. The dishes and the patterns of serving food symbolises household status. A village story tells about how social norms are linked to social prestige. Serving rice dishes at every meal is particularly important to people where rice production is very low as complements to dishes derived from millets, buckwheat, maize, potatoes or wheat. To secure household prestige, the cooks prepare two separate dishes one from rice and one from other cereals. These dishes are served in a strategic manner. The cook knows that people will still enjoy porridge when they are hungry. Such order of service probably reduces the chance to make any complaints against the food and the cooks in particular. There is a custom that a 'Bramhin' wearing sacred threads should leave small amounts of rice to give away to lowly spirits that appear as pet animals or birds. Again they need to put some rice aside and come out to wash their hands to prove that they have eaten rice. Belching is not liked though it is common after the good meal. Also to create a feeling that they have had a good meal, tastier dishes such as rice are served last. Such practices are rare for any meals taken in the evening, except those nights when the family is hosting visitors or relatives.

Social position of a household is relative, which may vary from one location to another and can be predicted against the dishes they serve. Farmers of low rice producing areas may secure higher social position if rice dishes are included in regular meals. The choices of species are important. Unlike Talium and Begnas, Kachorwa farmers select landraces within the rice crop. Prestige in such cases is based on whether the meals are prepared from quality landraces. In addition, the number of times dishes are served and the number of dishes that form the meal symbolise social prestige. Wealthier families with high social status serve more dishes than poorer families.

In all study villages, slightly different food privileges and serving patterns were found for men and women. The significant food privilege for men was unique to Talium. The regular meals and popular dishes are served to male members and children. In particular cases, women can have food privileges during her post delivery period. Women who gave birth to a boy (but not a girl) enjoy special food dishes ${ }^{1}$. In public celebrations, ceremonies and ritual functions, common dishes are served. The order foods are served follows head of household then men and then women. The children are served in the beginning or in separately. The cooks (woman) always take their meal last, and not with rest of the male members. There is a custom that the wife uses the same plate with the leftover meal after her husband. Prior to eating main meals, married women often greet their husbands. These sorts of traditions are still prevailed in rural villages e.g. Talium. The impacts of serving patterns and food preferences can be twofold. The household heads having food preferences may influence household decision in selecting particular landraces even if there are alternative options.

\section{SYMBOLIC TRADITIONAL DISHES}

Rice for Hindus is not only a staple crop but is also known to have diverse symbolic meanings. Rijal, et al., (1998) documented different rice dishes prepared from specific landraces are used for symbolic offerings to the Gods and Goddesses. Over 18 festivals and

\footnotetext{
${ }^{1}$ Delicious dish prepared from locally known rice landrace (Jumli marsi) with legume soup mixed with mutton
} 
nine ritual functions were reported to require a variety of rice dishes (Pant, 2002). None of the Indo-Aryan religious, ritual or cultural functions are complete without the inclusion of rice pudding (Khir). Special dishes are required for offerings to lowly spirits (Ghost), spiritual forces such as Gods, and lineage Gods. Descendants made symbolic offerings with rice balls (Pinda) to the past ancestors in rituals ceremonies (Shraddha) (Stone, 1978). 'Bramhin' male who have sacred threads use rice as symbolic offerings to their descendents prior to primary meals eat. Unlike rice, taro can have slightly different symbolic meanings. Descendents offer taro leaves to mediate spirits of past ancestors in ritual ceremonies. Since root crop species are considered "pure" taro corm/cormels are eaten during Hindu festivals specially Maghe Sakranti and Shiva Ratri. Specific landraces are chosen for such dishes and / or for social and religious functions. Hindu women will have to have cultural and religious meal prepared from taro landraces that produce single shoot and rice varieties of local origin. Farmers know that taro seeds planted without ploughing give single shoots. Those landraces with ritual or cultural values are often grown in small patches.

Our experience is that inter and intra species diversity has strong links with religious and social norms. Even today social status is among other things judged against: a) the amount of rice produced, b) the frequency aromatic rice is eaten at regular meals $c$ ) the number of quality rice varieties grown, and d) growing landraces with religious, cultural significance and special uses. Farmers with high rice diversity are ranked high in their societies. Social prestige seems to provide a certain degree of motivation to conserve crop landraces.

\section{TRADITIONAL TARO DISHES}

Like other species, taro provides ingredients for important dishes in the Nepalese diet. Local farmers prepare a variety of dishes from leaves, petioles and corm or cormel. The common ways different dishes are eaten include vegetables, curry and boiled and dip fries. Certain traits are preferred for specific dishes. Acridity is such a trait that is common in taro. Begnas farmer Chizamaya Gurung metaphorically compares acridity and states: "taro without acridity is to say like a snake without poison" but what matters for her is the degree of acridity. Since local techniques are developed to normalise acridity ${ }^{1}$, any promising landraces are still grown even if they are acrid.

Certain landraces are preferred for some dishes with other multiple uses. In Begnas, 'Dudhe karkalo' is known as a landrace for pickles, leaves and young shoots. 'Panchamukhe' and 'Khujure', both cormel types, are preferred for dishes prepared from leaves and shoots. In general, landrace diversity corresponds to the dietary richness. However, this is not always so. Talium and Kachorwa farmers prepare about six dishes from a single landrace. In Begnas, at least 13 different dishes are prepared whereas more than 16 landraces are grown. The study revealed that the majority of dishes are common dishes but a few dishes are location specific. In all villages, fresh leaves, shoots and cormel were identified as common items. Despite absolute uses, taro products are also used as ingredients in snacks or other curry or vegetable dishes.

'Pakauda' is such a popular dish and is eaten as midday snack in Kachorwa. Likewise, 'Masaura' is prepared from young shoots and also from the corm. However, these are prepared from shoots and also from corms. The fresh shoots or corms when cut in smaller pieces are semi-dried in the sun. The dish is prepared as soon as the raw materials are dried. Processed nuggets with a triangular shape, uniform size and green colour are preferred. To keep the natural colour and to avoid any bad smell, nuggets are dried under shed. Well-dried nuggets are packed in earthen or bamboo structures and can be stored for several weeks if kept in a dry place.

\footnotetext{
${ }^{1}$ Products are treated with lemon, salt and chilly powder

${ }^{2}$ Hexagonal shaped dip fried structure prepared from cut onions, flour and mashed potatoes or from taro. Popular in Kachorwa
} 
There are seasons or occasions during which certain dishes are preferred. "Masaura"1 for example, is considered as an all season dish whereas 'Tandra'" soup / curry is considered best when served during the dry season. The fresh leaves are eaten from summer until early winter, and corm and cormel during the spring months. The majority of the products are consumed in dry spring seasons particularly when fresh vegetables are in short supply. It is evident that in Begnas the richness of local dishes correlated positively with landraces diversity. In other villages, multiple dishes are prepared from a single landrace suggesting that use value differs from one landrace to another. The similar is in the case of Begnas. Landraces with multiple uses are popular compared to those with specific uses. Local dishes have served as a 'driving force' for conserving landraces. In other words, the promotion of local dishes enhances conservation of landraces along with food traditions. Through discussion, we recognize three bottlenecks that prevent their promotion: 1) traditional

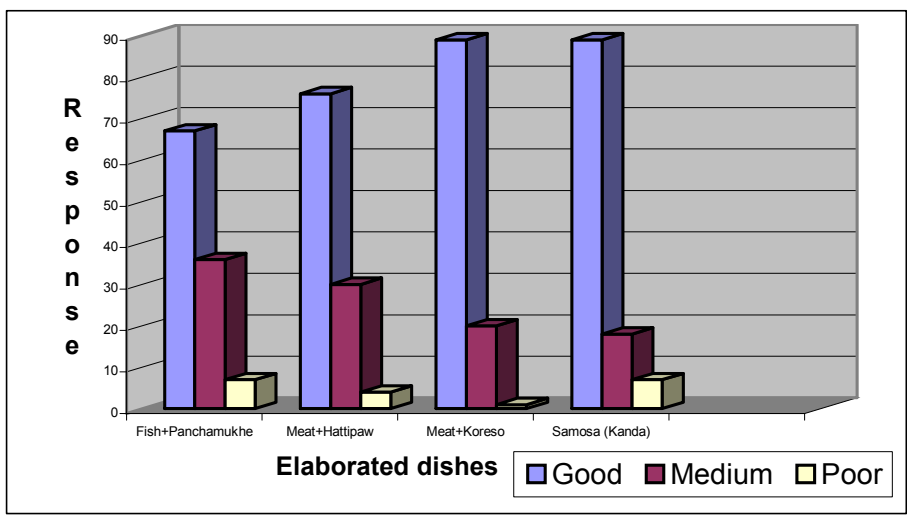
systems are not
good enough to
produce quality
products 2) there is
a lack of reliable
supply systems
throughout the
season as per
consumers' demand,
and 3) there is a
lack of local and
research base
information
including recipes as
per demand of
urban consumers.

Fig. 1: Panelist response to elaborated dishes

\section{ELABORATION OF TARO DISHES}

Traditional taro dishes were served alone or mixed with other ingredients. Farmers expressed that the taro tasted best when cooked with grain legumes or potatoes. Such practices are also occasionally seen in urban societies. We hypothesize that the demand for taro derived products will be expanded if: a) dishes are elaborated to make them more appealing and attractive, and b) consumers' access to elaborated dishes is improved. It was learned that poorly processed and packed dishes combined with unreliable supply are not attractive to urban consumers. We assume that local dishes need to be elaborated to make them appealing and attractive. Locally known dishes were elaborated and tested to examine consumers' preferences. Locally known traditional dishes were evaluated combined with popular items including fish, meat, legumes and Samosa.

\section{CULINARY CHARACTERS OF ELABORATED TARO DISHES}

The panellists liked all the elaborated dishes, although some dishes were preferred more than others. Samosa was assessed best with 'Ujarka'. Other preferred dishes were fish curry prepared with 'Panchamukhe' followed by dip fried mutton with 'Hatipow'. The most liked dishes are presented in Figure 1. 'Hatipow' seemed more compatible when cooked with

\footnotetext{
${ }^{1}$ A traditional triangular nugget made from taro petioles or corm and black gram flour, In Begnas, the dish is served to guests, visitors or close relatives. A gift pack of 'Masaura' is given to relatives, friends living outside village or abroad

${ }^{2}$ Item prepared from the young semi-dried shoots, chopped longitudinally and dried under the sun. They are weaved like a ponytail and hung in dry and protected places.
} 
mutton. 'Panchamukhe was largely preferred for curry dishes. All three panel groups unanimously rated 'Ujarka' to be the best landrace for Samosa. Certain trends were observed about consumers' preference. Farmers and housewives preferred dishes that are prepared with mutton followed by fish and legumes. Both farmers and housewives rated elaborated dishes in similar ways except for fish curry with 'Hatipow' and 'Samosa'. Farmers liked Koresho and 'Hatipow' with mutton and ranked 'Samosa' thereafter. Expert cooks and housewives liked 'Samosa' most and Koresho with the mutton thereafter. Curry dish when cooked with Tandra mixing with potatoes was disliked by farmers and housewives. Unlike farmers and housewives, curry mixed with peas and 'Hattipow' was surprisingly liked by expert cooks. Unlike expert cook and housewives, farmers also preferred Koresho even with peas (Figure 1, Annex 1).

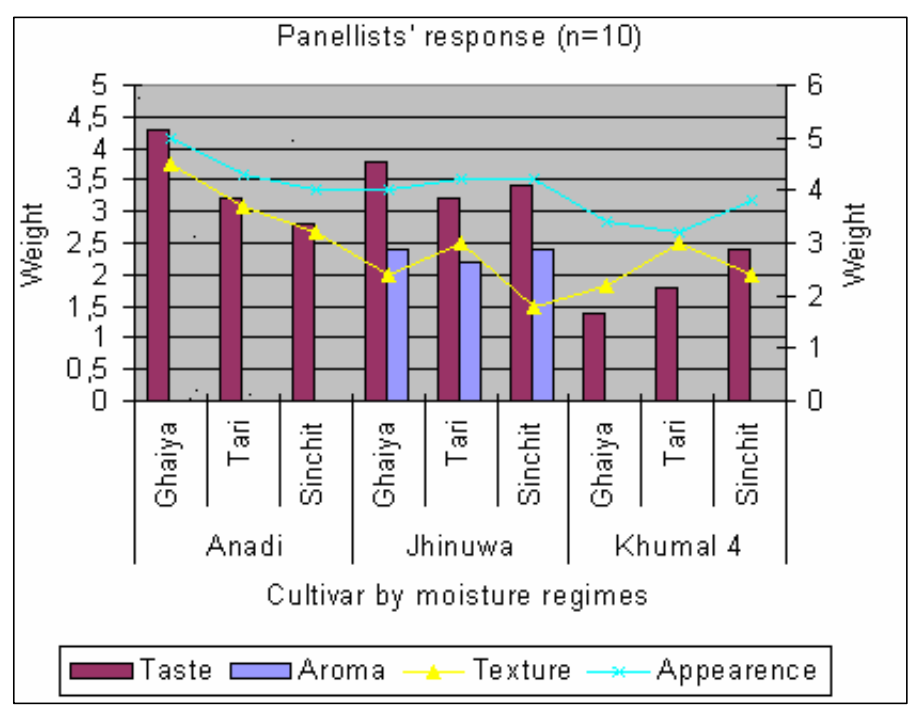

Response: Total panellist $\mathrm{x}$ individual ranking as Good (5), Medium (3) and Poor (1)

This shows the choices can be both common and panel group specific. It may, therefore, be unjust to generalise the preference trend based on the results of a limited panellist response. This information however, gives a basis for the selection of elaborated dishes for promotion purpose.

Fig. 2: Effects of moisture regimes on culinary characters of rice, Begnas Note: Higher the score greater the preference

\section{CULINARY CHARACTERS OF COOKED RICE}

The study revealed that the taste of cooked rice vary by ecosystem and cultivar types (landrace or improved). Both landraces 'Anadi' and 'Jhinuwa' had an even better taste when grown in the uplands. Khumal 4 an improved variety, on the other hand, had a better taste when grown under its originally recommended ecosystem. Unlike improved variety, both landraces gave promising results as far as culinary characters are concerned. The rice aroma was better when grown under Ghaiya and Sinchit than in Tari (Figure 2). Regardless of cultivar types, the texture of cooked rice was better when grown in Tari. However, 'Anadi' grown under upland ecosystem always tasted better.

The above results led us to make few remarks. Despite low yields, irrigated landraces can be grown under upland conditions as far as culinary character is concerned. Since farmers make their own choices of comparative benefits, the new options could be an effective method for the conservation of food and cultural diversities. Since improved varieties show specific adaptation they are rarely preferred when grown under upland conditions. Provided economic yields are competitive with other options farmers have, irrigated rice landraces had better quality grain when grown under rain fed and upland conditions. This suggests 
that culturally valued landraces even if displaced from their original habitats may be conserved in alternative production ecosystems.

\section{DISCUSSION AND IMPLICATIONS}

Nepalese food traditions are full of symbolic meanings and they vary according to the context that they are used and the way they are served. They have substance value if eaten as food, and the same dish is symbolic if it is offered as mediation to the Gods, Lineage Gods or lowly Spirits during ritual or religious functions. As Stone (1973) described, social prestige is directly linked to food traditions, and indirectly linked to crop landraces. Farmers' reasons for the present day landraces are the relative benefits and values e.g. substance and cultural. The ground where the present landraces are grown may change over time in accordance with changes in peoples' perception. Traditional food habit and the recipe that makes a complete meal play important role to maintain diversity. The recipes included in ordinary meals indicate food traditions play important roles in conserving diversity. Local preference for some crop species, varieties for specific dishes which are served either in ordinary meals, religious or cultural meals provide community incentive further to maintain diversity on-farm. Along with the socio-cultural and food values diversity is maintained due to environmental variation. As depicted in Figure 2 some landraces are preferred when grown under certain environment while others under different environments. For instance, the high quality rice landraces give real taste only when grown in their original habitats e.g. sinchit. This suggests that landraces are maintained for different non-material values, economic and ecological benefits.

These landraces that have multiple values and uses e.g. 'Jhinuwa rice' are likely to be maintained on-farm. Likewise, crops landraces with non-substance values are likely to be continued as long as social norms, culture and food tradition are maintained. The fate of landraces therefore is greatly dependent on the conservation of socio-culture, social norms and degree of compliance of food traditions with modern food science.

Landraces with specific uses are maintained because certain dishes are popular. The fate of landraces with substance value is however dependent on their potential to offer services and benefits to local people. Integration of such elaborated dishes derived from locally adapted and socially valued species in common cuisine may expand food markets. Elaborated taro dishes when integrated with mutton could be popular among urban consumers. The promotion of elaborated dishes may attract more consumers, which provide incentives to different parties including farmer- producers. Conservation of crop landraces can thus be strengthened, provided the demand for their derived products are created or expanded.

In addition to describing local food traditions, we present two different approaches through which market demand for crop landraces are created and or expanded. As indicated earlier, the elaboration of food traditions has been found effective in expanding consumers' demands. Most crop landraces are not as productive as modern varieties particularly when grown in fertile lowlands. It is imperative to explore ways and areas where such culturally valued but less productive crop landraces may be grown successfully. Research results have shown that some landraces grow well in alien environments suggesting that some landraces displaced from their original habitats, may be grown to newer habitats where farmers options are limited. This approach has shown that farmers can grow certain landraces even in new environments if the demand for their products could be expanded.

It is worth discussing how peoples' livelihoods are addressed when conserving food and cultural diversities. Food traditions are an important subset of the peoples' livelihoods. Livelihoods may be considered secure when consumers' have good access to traditions as per their preferences. Crop landraces that are often linked to local food traditions are 
being displaced with the growing popularity of the modern varieties. Farmers are thus being discouraged to continue growing crop landraces.

One way of creating farmers' incentive to continue crop landraces is through expanded demand for their derived products. Results have indicated that the promotion of elaborated foods benefits every actor involved from producers through to consumers. Urban consumers may introduce new dishes in their meals. As shown in Annex 2 traditional food habits that are developed based locally cultivated diversity are increasingly threatened along with improved access to exotic and processed foods including takeaways e.g. pancake, pizza, noodles and spagetty. Though increased diversity of food dishes help improve food and nutrition it only assures diversity maintenance only when new food recipes are developed based on the locally cultivated food crop species. To do that food research initiation should be given due attention.

The farmer benefits from landraces if the demands for derived products are increased. It is likely that increased income may allow farmers to buy cheaper foods (processed) accessed locally. Urban consumers benefit if elaborated dishes are supplied to the markets. Through such efforts the different actors would mutually benefit each other. Kahn (1988) argued that adding values to food traditions is not only to replace imported foods but also to provide more options for consumers. This would monopolise food markets through promoting food traditions but provide more options to consumers and thereby enhance peoples' livelihoods. If the multiple strategies as above are in place, we argue that diversities and livelihoods go hand by hand.

\section{REFERENCES}

Brush, S and E. Meng, 1998. Farmers' valuation and conservation of genetic resources, Genetic resources and crop evolution, 45: 139-150, Kluwer Academic Publisher, The Netherlands. Bellon, M.R and J.E Taylor, 1993. 'Folk' soil taxonomy and the partial adoption of new seed varieties. Economic Development and Cultural Change 41:763-787.

Bennett, J. W., 1943. Food and social status in a rural society, Americal Sociological Review, Vol. 8: 561-569, Washington D.C.

Charles, N. and M. Kerr, 1988. Women, food and families, pp: 141-164, Manchester University Press, Mancheter and Newyork, ISBN:0-7190-1874-9 hardback.

Detienne, M. and J. P. Vernant, 1989. The Cuisine of Sacrifice Among the Greeks. London: The University of Chichgo Press.

Douglas, M., 1997. Deciphering the Meal, In: C. Counihan and P. Van Esterik (eds.), Food and Culture, Routledge Publishers, pp 36-54

Goody, J., 1991. The Impacts of the World System, Cooking, Cuisine and Class: A Study in Comparative Sociology, pp. 175-190, Cambridge University Press.

Hue, N. T. N., 2000. Taro Diversity and Use in Vietnam, Diversity of taro (Colocasia esculenta L) through use in Nepal, In: Ethnobotany and Genetic Diversity of Asian taro: Focus on China, pp 1825. Procceding of the Symposium on Ethonbotanical and Genetic Study of taro in China: Approaches for the Conservation and use of Taro Genetic Resources, 12-17 November, 1998, Laiyang Agricultural College, Liayang, Shangdong, China, ed. D.Zhu, P.B. Eyzaguirre, M. Zhou, L. Sears.

Kahn, M., 1988. Men are taro (they cannot be rice): political aspect of food choices in Wamira, Paupua New Guinea. Food and Food Ways, Vol. 3: 41-57, Harwood Academic Publishers GmbH.

Kiple, K. W., 2000. The social and cultural uses of food, In: Kiple and Ornelas (eds.) The Cambridge World History of Foods, vol. 2, pp.1513-1523, Cambridge University Press.

Pant, L.P., 2002. Linking crop diversity with food traditions and food security in the hills of Nepal. A Thesis submitted in the partial fulfilment of the requirement of the degree of Masters of Science in Management of Natural Resources and Sustainable Agriculture, Agricultural University of Norway.

Pandey, Y. R., D. K. Rijal and B. R. Sthapit, 2000. Diversity of taro (Colocasia esculenta L) through use in Nepal. In: Ethnobotany and genetic diversity of Asian taro: focus on China, Procceding of the 
symposium on ethonbotanical and genetic study of taro in China: approaches for the conservation and use of taro genetic resources, 10-12 November, 1998, Laiyang Agricultural College, Liayang, Shangdong, China, ed. D.Zhu, P.B. Eyzaguirre, M. Zhou, L. Sears, pp. 18-25.

Rijal, D. K, R. B. Rana, M. P. Upadhyay, K. D. Joshi, D. Gauchan, A. Subedi, A. Mudwari, S. P. Khatiwada and B. R. Sthapit, 2001. Adding benefits to local crop diversity as a sustainable means of on-farm conservation: a case study of an In situ project from Nepal. An Exchange of Experiences from South and South East Asia, Proceedings of the International Symposium on Participatory Plant Breeding and Participatory Plant Genetic Resource Enhancement, ISBN 958-694-040-3.

Rijal, D. K, R. B Rana, P. R. Tiwari, L. P. Pant and D. I. Jarvis, 2001. Promoting local food culture as a method to conserve buckwheat diversity in agro-ecosystems in Nepal. In: H. P. Bimb and B. K Joshi (eds.), Proceedings of national workshop on research and development on buckwheat, Kathmandu, Nepal, 13-14 Sept 2001.

Smale, M., 2000. Economic incentives for conserving genetic diversity on-farm: issues and evidences, summary of the paper prepared for the meetings of the international agricultural economics associations, Berlin, August 12-19, 2000.

Stone, L., 1978. Food symbolism. In: Hindu Nepal (ed.), Contribution to Nepalese Studies/Journal of Centre for Nepal, Institute of Nepal and Asian Studies, Tribhuvan University, Kathmandu, Nepal.

Weismantel, M. J., 1988. Food, Gender and Poverty in the Ecudorian Andes. Philadelphia: University of Pennsylvania Press, ISBN 0-8122-8115-2.

Zimmerer, K. S. and D. S. Douches, 1991. Geographical approaches to native crop research and conservation: the partitioning of allelic diversity in Andean potatoes. Economic Botany, 45:176-189.

Annex 1: Results of sensory evaluation of elaborated dishes, LI-BIRD (2002)

\begin{tabular}{l|l|l|l}
\hline Panel group/Elaborated dishes & Expert cook & House wives & Farmer \\
\hline 1. Fish curry + Panchamukhe & 4.4 & 4.2 & 3.9 \\
2. Fish curry + Hattipaw & 4.0 & 4.3 & 3.7 \\
3. Fried mutton + Hattipaw & 4.6 & 4.3 & 4.3 \\
4. Curry peas + Panchamukhe & 3.4 & 4.0 & 3.8 \\
5. Curry peas + Hattipaw & 4.5 & 3.6 & 3.4 \\
6. Curry peas + Koreso & 3.3 & 3.8 & 3.8 \\
7. Fried mutton + Koreso & 4.6 & 4.7 & 4.6 \\
8. Mutton curry + tandre + Patato & 3.5 & 3.5 & 3.3 \\
8. Samosa (Ujarka) & 5.3 & 4.9 & 4.1 \\
\hline
\end{tabular}

Note: Panellist given score $\mathrm{x}$ rating score for each good (5), medium (3) and poor (1) / total potential responses by consumer category 
Annex 2: Description of regular cuisines of Talium, Begnas and Kachorwa villages, Nepal.

\begin{tabular}{|c|c|c|c|}
\hline \multirow{2}{*}{$\begin{array}{l}\text { Meals in priority } \\
\text { order, } \mathrm{I}=\mathrm{High}\end{array}$} & \multicolumn{3}{|c|}{ Villages } \\
\hline & Talium (Mountain) & Begnas (Mid-hill) & Kachorwa (Tarai) \\
\hline $\begin{array}{l}\text { III. Breakfast or } \\
\text { Bihanko Khaja } \\
(6-8 \mathrm{am})\end{array}$ & $\begin{array}{l}\text { a. Tea }(\mathrm{C}+ \\
\text { b. Boiled potatoes/ } \\
\text { c. Millet bread/ } \\
\text { d. Roasted barley flour } \\
\text { e. Noodles } \\
\text { f. Left over meals served } \\
\quad \text { to children }\end{array}$ & $\begin{array}{l}\text { a.Tea }(++ \\
\text { b. Boiled egg (0) } \\
\text { c. Puffed com/ } \\
\text { d. Puffed soybean or } \\
\text { d. Noodles or } \\
\text { e. Milk only } \\
\text { f.Left over meals served to } \\
\quad \text { children }\end{array}$ & $\begin{array}{l}\text { a. Tea }(+) \\
\text { b. Boiled egg (O) } \\
\text { c.Beaten rice+yogurt+Cury } \\
\text { d. Biscuits / } \\
\text { e. Noodles/ } \\
\text { f. Bread /Loaf/ } \\
\text { g. Milk only or } \\
\text { h. Left over meals served to children }\end{array}$ \\
\hline $\begin{array}{l}\text { I. Morning meal } \\
\text { or Bhat } \\
(9-10 \mathrm{am})\end{array}$ & $\begin{array}{l}\text { a. Vegetable curry (C+ } \\
\text { b. Beans soup/ } \\
\text { c. Fermented dish (OS) } \\
\text { c. Boiled rice / } \\
\text { d. Millet bread } \\
\text { e. Whey (O) } \\
\text { f. Yogurt (O) }\end{array}$ & $\begin{array}{l}\text { a. Vegetable cury } @ \\
\text { b. Legume soup/ } \\
\text { c. Fermented Dish (OS) } \\
\text { d. Boiled rice / } \\
\text { e. Boiled maize grit / } \\
\text { f. Millet porrige / } \\
\text { g. Milk / whey+ } \\
\text { h. Pickle+ }\end{array}$ & $\begin{array}{l}\text { a. Vegetable curry } \subset++ \\
\text { b. Legume soup+/ } \\
\text { c. Fermented Dish (OS) } \\
\text { d. Boiled rice@+ } \\
\text { e. Yogurt or whey (O) } \\
\text { f. Fried potatoes (F)+ } \\
\text { g. Nutrella (OS) } \\
\text { h. Pickle + } \\
\text { i. Ripen mango (S) + }\end{array}$ \\
\hline $\begin{array}{l}\text { II. Midday snack / } \\
\text { Diusoko Khaja } \\
(2-3 p m)\end{array}$ & $\begin{array}{l}\text { a. Tea C+ } \\
\text { b. Millet bread / } \\
\text { c. Buckwheat bread / } \\
\text { d. Boiled potatoes / } \\
\text { e. Puffed com + Whey } \\
\text { f. Noodles }\end{array}$ & $\begin{array}{l}\text { a. Tea (c+ } \\
\text { b. Beaten rice +Yogurt } \\
+ \text { Curry } \\
\text { c. Sweets + Curry / } \\
\text { d. Samosa + Yogurt / } \\
\text { e. Biscuits/bread / } \\
\text { f. Puffed com+ Whey/ } \\
\text { g. Puffed rice + Pickle } \\
\text { h. Noodles } \\
\text { i. Wheat chapati + } \\
\text { Vegetable cury }\end{array}$ & $\begin{array}{l}\text { a. Tea } \odot++ \\
\text { b. Beaten rice+Yogurt + Curry/ } \\
\text { c. Samosa + Yogurt/ } \\
\text { d. Sweets + curry / } \\
\text { e. Boiled potatoes + Whey/ } \\
\text { f. Puffed maize + Whey/ } \\
\text { g.Puffed rice+Fried } \\
\text { potatoes/ } \\
\text { h. Biscuits/bread } \\
\text { i. Noodles } \\
\text { j. Wheat chapati + Vegetable cury }\end{array}$ \\
\hline $\begin{array}{l}\text { I. Evening meal / } \\
\text { Belukako Khana } \\
\text { (6-7pm) }\end{array}$ & $\begin{array}{l}\text { a.Vgetable curry / } \\
\text { b. Beans soup+® } \\
\text { c. Millet bread } \\
\text { d. Buck wheat bread / } \\
\text { e. Boiled rice (P) } \\
\text { f. Barley + millet bread/ } \\
\text { g. Wheat bread } \\
\text { h. Whey + } \\
\text { i. Meat (OC) } \\
\text { j. Fish } ® \\
\text { k. Egg }{ }^{\circledR}\end{array}$ & $\begin{array}{l}\text { a. Vegetable curry / } \\
\text { b. Black gram soup @ / } \\
\text { c. Masaura (OS)/ } \\
\text { d. Nutrella (OS)+ } \\
\text { e. Maize grit / } \\
\text { f. Wheat bread / } \\
\text { g. Millet porrige / } \\
\text { h. Whey + } \\
\text { i. Meat (OC) } \\
\text { j. Fish (FSS) } \\
\text { k. Egg }{ }^{\circledR}\end{array}$ & $\begin{array}{l}\text { a. Vegetable curry } \subset \\
\text { b. Lentil soup } \subset+\text { / } \\
\text { c. Nutrella (F) } \\
\text { d. Wheat bread / } \\
\text { e. Cooked rice / } \\
\text { f. Milk or whey+ } \\
\text { g. Meat (OC) } \\
\text { h. Fish (FSS) } \\
\text { i. Egg (F) }\end{array}$ \\
\hline
\end{tabular}

Note: $\odot=$ common element, $0=$ optional dishes, ${ }^{\circledR}=$ Rarely served dish, FSS=Frequently served dish in particular season, OC=Dish served in special occasion, OS=Off-season served dish, $/=$ Alternative or optional element of a meal,+/=Dish served along with or with alternative dish. Bold dishes are imported or junk foods or those foods replacing local foods. Source: Focus group discussion (2002).

\section{ACKNOWLEDGEMENTS}

The work was supported by the International Plant Genetic Resources Institute (IPGRI) through a global project, Nepal Agricultural Research Council and Local Initiatives for Biodiversity, Research and Development with involvement of farming communities in Talium, Begnas and Kachorwa villages. The author acknowledges Dr. Karus Randi of Noragric of the Norwegian University of Life Sciences Norway and Dr. Devra Jarvis of Bioversity International for their sincere guidance to prepare this manuscript, Ms. Arshiya Noorani of the Bioversity International for her assistance in reviewing the manuscript, LIBIRD staffs particularly P.R. Tiwari, I.P. Poudel, S.R. Subedi and F.K. Chaudhary for their support in the field. 